\title{
APLICAÇÃO DE DISPERSANTES TENSOATIVADOS NO CONTROLE DE REBOCO, FILTRADO E NO DESENVOLVIMENTO DE POÇOS TUBULARES
}

\author{
USE OF TENSOACTIVE DISPERSANT IN THE CONTROL OF THE FILTER-CAKE, WATER LOSS \\ AND DEVELOPMENT OF TUBULAR WELLS
}

\author{
Kássie Vieira Farias ${ }^{1}$, Luciana Viana Amorim² ${ }^{2}$ Eugênio Pereira ${ }^{3}$, Heber Carolos Ferreira ${ }^{4}$
}

\begin{abstract}
RESUMO Este trabalho tem como objetivo avaliar a aplicação de dispersantes com e sem tensoativos no controle do reboco, do filtrado e da reologia de fluidos de perfuração hidroargilosos. Foram estudadas três amostras de aditivos dispersantes denominados de Hexa (sem tensoativos), Hexa T (com tensoativo) e Spersene. Os fluidos de perfuração foram preparados com 4,86\% em massa de argila bentonítica sódica, proveniente de Boa Vista, PB. A preparação dos fluidos e a determinação das viscosidades aparente e plástica e do volume de filtrado, antes e após a aditivação, foram realizados de acordo com as normas N-2605 da Petrobras. A espessura do reboco foi determinada utilizando-se uma metodologia baseada na norma 13B-1 da API. Foram também realizados ensaios de caracterização dos aditivos dispersantes e ensaios de simulação da ação dos dispersantes, em fluidos de limpeza conhecidos como "colchão lavador", no desenvolvimento de poços tubulares. Os resultados evidenciaram a importância da utilização conjunta de agentes dispersantes e tensoativos na formulação de aditivos a serem empregados em fluidos hidroargilosos na prevenção ou solução de problemas causados pela presença de rebocos muito espessos, bem como indicaram que estes podem auxiliar no processo de limpeza de poços, tornando esta etapa mais eficiente e com possibilidade de melhora na produtividade de poços tubulares.
\end{abstract}

Palavras-chave: dispersantes, tensoativos, fluidos

\begin{abstract}
The aim of this work is to evaluate the use of dispersant with and without tensoactive over filter-cake, water loss and rheology of the water based drilling fluids. Three samples dispersant additives, called Hexa (without tensoactive), Hexa T (with tensoactive) and Spersene were studied. The drilling fluids were prepared with $4.86 \% \mathrm{w} / \mathrm{w}$ of sodium bentonite clay from Boa Vista, PB and determinate the apparent and plastic viscosities and the water loss before and after treatment with additives according to Petrobras N-2605 standard. The filter-cake thickness was determinate using methodology based on API 13B-1 standard. Also, it was done the characterization of the dispersant additives and the simulation of the action of the dispersant additives as "washing fluids" in the development of tubular wells. The results shows the importance to using dispersant and tensoactive agents simultaneously in formulating additives for drilling fluids to prevent or solve thick filter-cake problems. Besides, it may help in the cleaning process to improve the efficiency and the productivity of the well.
\end{abstract}

Keywords: dispersant, tensoactive, fluids

\section{INTRODUÇÃO}

Segundo Lummus e Azar (1986), os fluidos de perfuração devem ser capazes de produzir nas paredes do poço uma membrana fina de baixa permeabilidade, denominada reboco, importante para consolidar a formação geológica, garantindo a estabilidade do poço, a redução da perda de filtrado, ou seja, o escoamento da fase contínua do fluido para o interior das formações geológicas e ainda a segurança da perfuração. $\mathrm{O}$ reboco é formado pela deposição de sólidos presentes no fluido nas paredes do poço à medida que a fase contínua (água) deste penetra nos seus poros. A espessura do reboco aumenta enquanto o fluido ceder água às formações geológicas, com as quais está em contato, até conseguir impermeabilizar o envoltório do poço, impedindo a perda de água por filtração (Ferraz, 1977).

Colaboram neste processo o teor de sólidos e a aptidão selante dos materiais que compõe o fluido de perfuração.

De acordo com Pereira (2003), a falta de controle da espessura do reboco pode causar diversos problemas durante a perfuração, como: invasões excessivas de filtrado nas formações geológicas, desmoronamento de formações hidratáveis, redução do diâmetro do poço, aprisionamentos da coluna de perfuração, prisões diferenciais, danos às formações aquíferas e avaliações equivocadas das formações investigadas.

Ainda segundo o autor, a prisão diferencial representa alto risco à perfuração e ocorre quando a ferramenta de perfuração é presa, imobilizada (sem rotação), mas com o fluido circulando normalmente.

${ }^{1}$ kassievieira@hotmail.com ${ }^{2}$ luciana@cct.ufcg.edu.br ${ }^{3}$ eugenio@systemmud.com.br ${ }^{4}$ heber@dema.ufcg.edu.br 
Ela está associada a fluidos de perfuração inadequados, com teores de sólidos excessivos, densidades elevadas, altas taxas de filtrado e reboco espesso. A Figura 1 representa esquematicamente a prisão diferencial segundo um exemplo hipotético.

Segundo Pereira (2003), colagens ou aderências podem ocorrer em qualquer intervalo da profundidade do poço, onde houver desvio da verticalidade. A maioria dos poços não é totalmente vertical e é bastante comum terem suas paredes tocadas pela ferramenta, principalmente em conexões e manobras. Essas paredes são pressionadas fortemente pela coluna de fluido, criando um diferencial de pressão. De acordo com a figura 1, observa-se que o fluido exerce uma pressão de 5000 psi contra o comando, enquanto a pressão da formação é de 4500 psi, gerando assim uma diferença de pressão de 500 psi. O comando ao entrar em contato com o envoltório face a uma zona permeável, parte da coluna de comandos (6 m) pode embutir-se no reboco. A pressão hidrostática antes distribuída uniformemente ao seu redor (situação A), passa a ficar isolada a um lado (situação B) pressionando fortemente a coluna de perfuração contra a parede. Um processo de deposição de reboco contínuo vai envolvendo o tubo, fixando-o ainda mais ao envoltório. A magnitude desta pressão de colagem condicionará a dificuldade em sua liberação.

Poços perfurados com um controle de fluido dificilmente apresentam este problema. A formulação de fluidos com baixo teor de sólidos, controle de filtrado, reboco, viscosidade e peso durante toda perfuração promoverá à formação de um reboco adequado, evitando o aprisionamento da coluna de perfuração (PEREIRA, 2003).

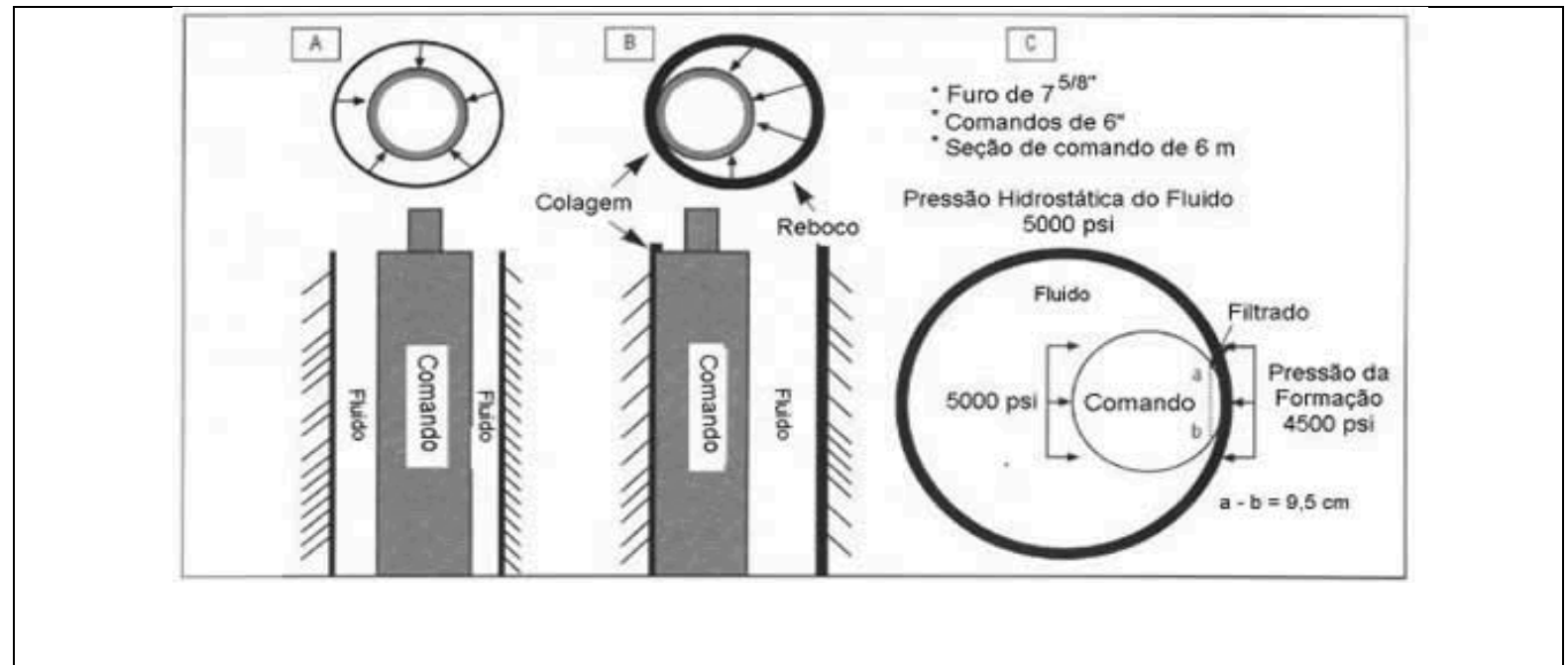

Figura 1 - Representação Esquemática do Aprisionamento da Coluna de Perfuração. Fonte: Pereira (2003). Figure 1 - Schematical Representation of the Imprisonment of the Drilling Column.

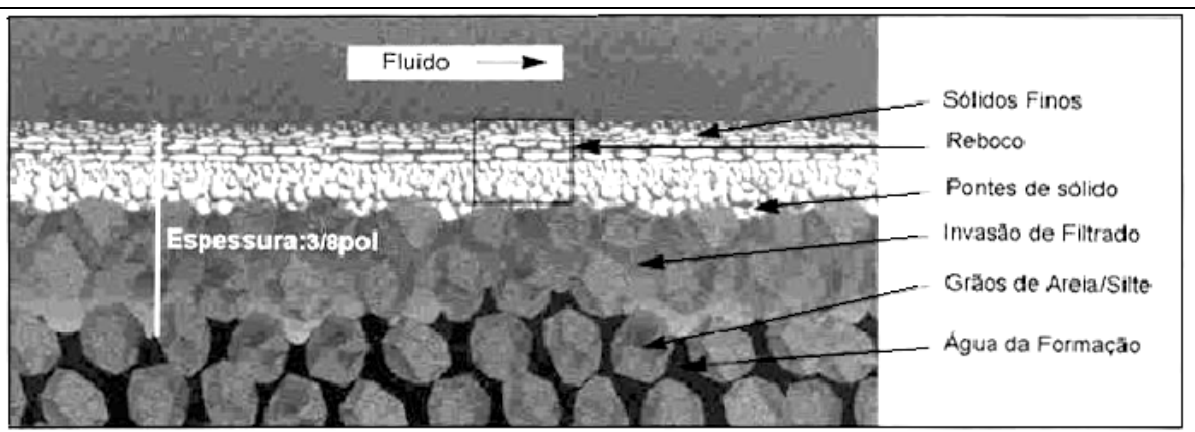

Figura 2 - Perfil Esquemático de um Envoltório de um Fluido Utilizado em Perfuração Rotativa. Fonte: Pereira (2003).

Figure 2 - Schematical Profile of the Involvement of a Fluid Using in Rotating Well. 
Segundo Pereira (2003), o uso de aditivos específicos, como dispersantes e tensoativos, será fundamental na solução dos problemas gerados por reboco muito espesso e falta de controle de filtrado.

Os dispersantes são substâncias que têm como principal função reduzir a atração entre as partículas de argila tornando-as dispersas no meio líquido, com conseqüente redução na viscosidade e no limite de escoamento do fluido hidroargiloso. Exemplos de dispersantes são os lignosulfonatos, os lignitos, os taninos e vários fosfatos.

De acordo com Pires (2002), os tensoativos são moléculas anfifílicas, isto é, possuem na mesma estrutura duas regiões de polaridade opostas: uma polar (ou hidrofílica) com afinidade pela água e outra apolar (ou hidrofóbica) com afinidade por outros solutos (Figura 3). Os tensoativos têm sido adicionados ao sistema bentonita-água para interagir com as partículas de argila, de acordo com sua característica iônica ou não-iônica. Os tensoativos iônicos induzem interações eletrostáticas, enquanto os tensoativos não-iônicos são adsorvidos na superfície por interações estéricas, que ocorre quando partículas são recobertas com uma camada de uma molécula de cadeia suficiente longa para dificultar, por impedimento físico, que as partículas se aproximem de região de forte atuação de forças de Van der Waals.

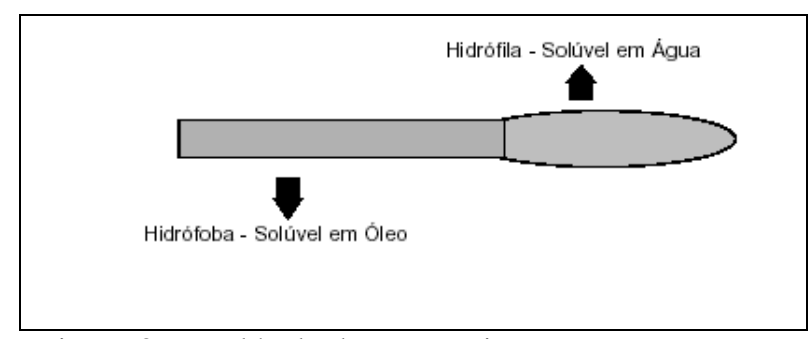

Figura 3 - Molécula do Tensoativo.

Figure 3 -Molecule of the Tensoative.

Segundo Gungor et al., (2001), as moléculas de tensoativos podem atrair ou repelir as partículas de argila e penetrar entre as camadas, podendo assim aumentar ou diminuir a estabilidade do sistema .

O sistema pode ser estável (defloculado) ou floculado, dependendo do modelo de interação. É possível controlar essa estabilidade através do controle das propriedades reológicas, viscosidades aparente e plástica, volume de filtrado e espessura de reboco com adição de tensoativos em concentrações apropriadas.

Estudos com o objetivo de avaliar as características do reboco (espessura e permeabilidade) e com a metodologia empregada para medição da sua espessura são ainda escassos na literatura. Um estudo do efeito da concentração de argila nas propriedades de filtração de suspensões de bentonita sódica foi realizado por Benna et al. (2001). Os resultados evidenciaram que com o aumento da concentração da argila, a espessura de reboco aumenta, o filtrado diminui e conseqüentemente diminui a permeabilidade.

O objetivo deste trabalho é avaliar a aplicação de dispersantes com e sem tensoativos no controle do reboco, do filtrado e da reologia de fluidos hidroargilosos, bem como na etapa de desenvolvimento de poços tubulares.

\section{ETAPA EXPERIMENTAL: MATERIAL}

\section{Argilas Bentoníticas}

Foram estudadas duas amostras de argilas bentoníticas na forma sódica, sendo uma industrializada em Campina Grande, PB pela Empresa Bentonit União Nordeste - BUN, comercialmente conhecida como Brasgel PA, e policatiônica e transformada em sódica em laboratório, denominada de Verde-lodo. A argila Verde-lodo e as argilas que compõem a amostra Brasgel PA são provenientes das jazidas de Boa Vista, PB.

\section{Aditivos}

Foram utilizadas três amostras de aditivos dispersantes: uma amostra com formulação normal com a presença do tensoativo, comercialmente conhecida por Hexa $\mathrm{T}$, outra amostra do mesmo aditivo que foi confeccionada especialmente sem a presença do tensoativo, sendo denominada de Hexa neste artigo e uma amostra de um dispersante utilizado em fluidos há várias décadas, principalmente no setor de petróleo, comercialmente conhecido por Spersene. As amostras dos aditivos Hexa $\mathrm{T}$ e Hexa foram fornecidas pela Empresa System Mud Indústria e Comércio Ltda, localizada na rua Otávio Muller, 204, Carvalho, Itajaí, SC e o Spersene pela Trionic Indústria e Comércio Ltda, localizada na Rua Guajarás 393, São Paulo, SP.

Hexa e o Hexa $T$ são dispersantes constituídos de um "blend" de polifosfatos de sódio e o Spersene é constituído por uma mistura de lignosulfonato de sódio, produto derivado da lignina da madeira que possui propriedades de dispersante primário. $\mathrm{O}$ detalhamento sobre a composição específica de cada produto é de posse exclusiva de seus fabricantes. 


\section{MÉTODOS}

\section{Caracterização dos Aditivos}

Para a caracterização dos aditivos foram preparados fluidos com a argila Brasgel PA de acordo com o item 2.2.2 e determinadas as viscosidades aparente e plástica e o volume de filtrado de acordo com o item 2.24 e a espessura do reboco de acordo com o item 2.2.5.

$\mathrm{s}$ fluidos foram tratados com os aditivos Hexa T, Hexa e Spersene nas concentrações de 0,5, 2,5, e 5,0g/ 24,3g de argila. Essas serão indicados no texto como $0,5,2,5$ e $5,0 \mathrm{~g}$.

O objetivo destes ensaios foi o de avaliar comparativamente a efetividade de cada aditivo, em concentrações idênticas. Neste caso, os parâmetros mínimos de viscosidades aparente e plástica e máximo de volume de filtrado não foram levados em consideração.

\section{Preparação dos Fluidos Hidroargilosos}

Os fluidos foram preparados com concentração de $4,86 \%$ em massa de argila (24,3g de argila em $500 \mathrm{~mL}$ de água deionizada) de acordo com a norma N-2605 (Petrobras, 1998). Todos os valores expressados em gramas neste artigo, para efeito de dosagem ou concentração, sempre estarão relacionados ao volume de $500 \mathrm{~mL}$, conforme a norma Petrobras.

\section{Aditivação}

Os aditivos estudados (Hexa, Hexa $\mathrm{T}$ e Spersene) foram incorporados individualmente aos fluidos sob agitação em agitador mecânico Hamilton Beach, modelo 936 durante 5 minutos nas seguintes concentrações: $0,025 \mathrm{~g} / 24,3 \mathrm{~g}$, $0,050 \mathrm{~g} / 24,3 \mathrm{~g}, \quad 0,100 \mathrm{~g} / 24,3 \mathrm{~g}, \quad 0,150 \mathrm{~g} / 24,3 \mathrm{~g}$, $0,200 \mathrm{~g} / 24,3 \mathrm{~g}, 0,250 \mathrm{~g} / 24,3 \mathrm{~g}$ e $0,300 \mathrm{~g} / 24,3 \mathrm{~g}$ de argila seca. No texto, essas concentrações serão indicadas como $0,025 \mathrm{~g}, 0,050 \mathrm{~g}, 0,100 \mathrm{~g}, 0,150 \mathrm{~g}$, $0,200 \mathrm{~g}, 0,250 \mathrm{~g}$ e $0,300 \mathrm{~g}$. Após $24 \mathrm{~h}$ foi realizado o estudo reológico como descrito no item 2.2.4 e determinada a espessura do reboco como descrito no item 2.2.5.

\section{Estudo Reológico}

Foram determinadas as viscosidades aparente (VA) e plástica (VP), em viscosímetro Fann 35A e o volume de filtrado (VF) em filtro prensa Fann segundo norma N-2605 (Petrobras, 1998). Os dados de VA, VP e VF serão comparados com os padrões especificados pela Petrobras (1998a) para fluidos à base de água e argilas bentoníticas, ou seja, $\mathrm{VA} \geq 15,0 \mathrm{cP}, \mathrm{VP} \geq 4,0 \mathrm{cP}$ e $\mathrm{VF} \leq$ $18,0 \mathrm{~mL}$.

\section{Determinação da Espessura do Reboco}

Para a determinação da espessura do reboco foi desenvolvida no LABDES (Laboratório de Referência em Dessalinização) uma metodologia baseada na norma API 13B-1 (API, 2003). Essa metodologia consiste nas etapas apresentadas a seguir.

Inicialmente, é coletado o papel de filtro com o reboco após a realização do ensaio para determinação do volume de filtrado. Em seguida, esse papel de filtro é lavado por três vezes a uma vazão de aproximadamente $110 \mathrm{~L} / \mathrm{h}$ com auxilio de um recipiente de nível constante com vazão regulável (Figura 4), a uma distância de aproximadamente $7,0 \mathrm{~cm}$ do controlador de vazão com diâmetro de $15,0 \mathrm{~mm}$ e com ângulo de ataque do fluxo da água de aproximadamente $45^{\circ}$. Após a lavagem para retirada do excesso do fluido na superfície do reboco, o papel de filtro com o reboco é colocado entre duas lâminas de vidro confeccionadas com o mesmo diâmetro do papel de filtro (Figura 5). A seguir, o papel de filtro com o reboco entre as lâminas de vidro é submetido a uma pressão de aproximadamente $277,6 \mathrm{~N} / \mathrm{m}^{2}$ por um período de $2 \mathrm{~min}$ com a finalidade de uniformizar a superfície do reboco.

Após esse período é medida a espessura do reboco com o auxílio de um extensômetro (Figura 6). São feitas cinco medidas das espessuras das lâminas de vidro e do papel de filtro com o reboco em pontos distintos, como mostra a Figura 7. Após obtenção das medidas, é feita uma média aritmética das cinco determinações e descontada a espessura das duas placas de vidro e do papel de filtro molhado, sendo determinada a espessura do reboco (ER) em milímetros com aproximação em centésimos.

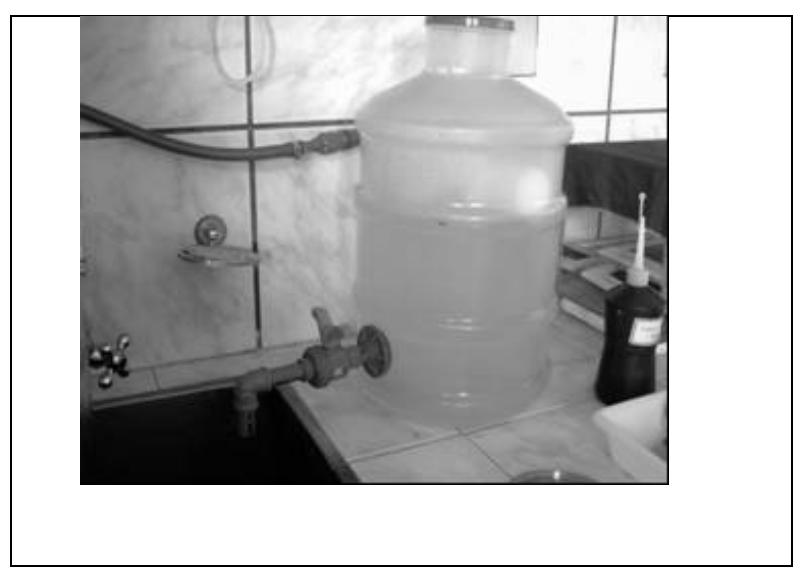

Figura 4 - Recipiente de Nível Constante com Vazão Regulável.

Figure 4 - Container of Constant Level with Regulable Outflow. 


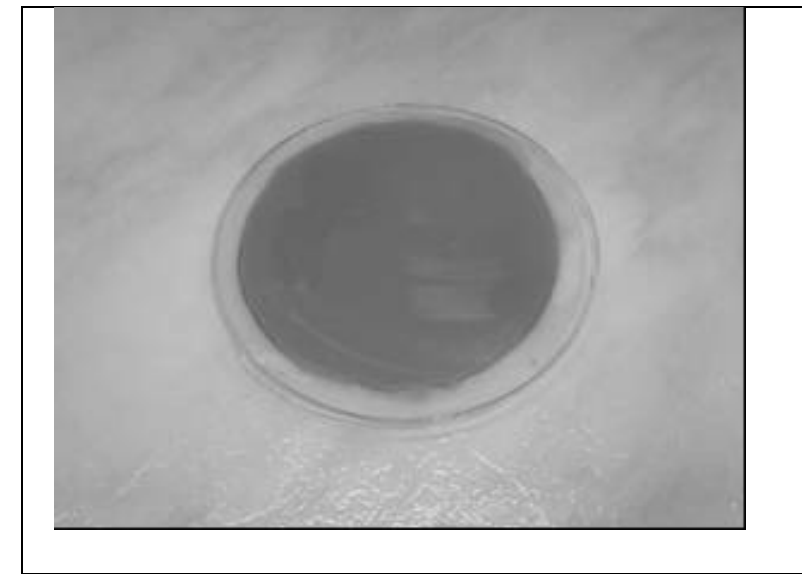

Figura 5. Lâminas de Vidro e Papel de Filtro de Mesmo Diâmetro.

Figure 5. Glass Blades and Filter Papers of Same Diameter.

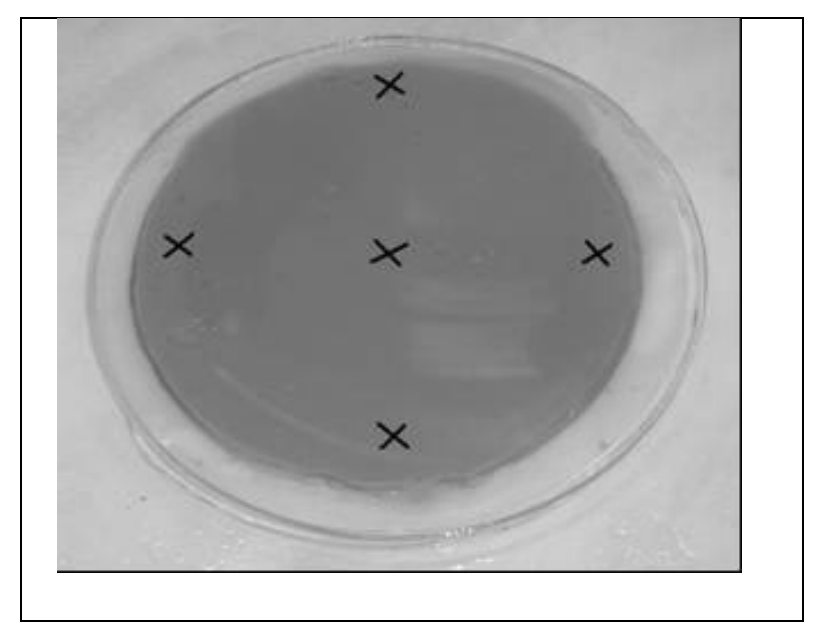

Figura 6 - Extensômetro Utilizado para Medição da Espessura do Reboco.

Figure 6 - Extensometer Used for Measurements of Filter cake Thickness.

\section{Simulação da Ação dos Dispersantes no} Desenvolvimento - Ensaio do Disco Boiando

Para avaliar a ação dos dispersantes, com e sem tensoativos durante a etapa de desenvolvimento, foram realizados ensaios denominados de Ensaios de Disco Boiando que consiste em uma simulação na qual rebocos obtidos a partir de fluidos preparados com a argila Brasgel PA permanecem em contato com uma solução sintética por 6h (Figura 8), semelhante à utilizada para a confecção do “colchão lavador", para empedregulhamento do poço pelo método do contra-fluxo. Neste método, circula-se uma solução pelo espaço anular com dosagens variadas de dispersantes e/ou hipoclorito de sódio ("colchão") antes de aplicar o pré-fluido, objetivando um tratamento prévio do reboco para facilitar sua remoção durante a etapa de desenvolvimento.

$\mathrm{O}$ reboco permaneceu em contato com a solução sintética (concentração de dispersante em torno de $3 \%$ ) por $6 \mathrm{~h}$, sendo realizadas medidas sistemáticas de ER após 1, 3 e 6 h. Ressaltam-se as dificuldades encontradas para estas medições já que os rebocos eram medidos após os períodos de tempo estipulados e voltavam para o contato com a solução. Levou-se em conta a tendência geral dos resultados e, principalmente, os aspectos físicos observados.

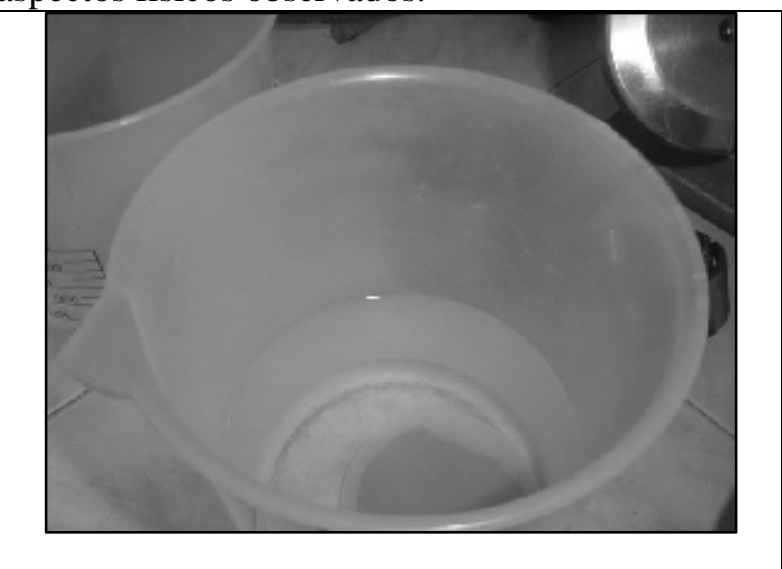

Figura 8 - Detalhe do Reboco em Contato com Solução Sintética.

Figure 8 - Detail of the Filter-cake in Contact with the Synthetic Solution.

\section{RESULTADOS E DISCUSSÃO}

\section{Caracterização dos Aditivos}

Os resultados obtidos com os fluidos preparados com a argila Brasgel PA tratados com os aditivos Hexa T, Hexa e Spersene estão apresentados nas Figuras 9 a 11.

Para os fluidos aditivados com Hexa $\mathrm{T}$ a redução de VA, VP, VF e ER foi expressivamente maior que os aditivados com Hexa (Figuras de 9 e 11). Estes resultados evidenciaram a ação do tensoativo em concentração menores $(0,5 \mathrm{~g})$, na diminuição do reboco; observa-se a queda abrupta da curva no intervalo de 0 a 0,5 g em Hexa T (Figura 9) e o comportamento mais suave com Hexa (Figura 10). 


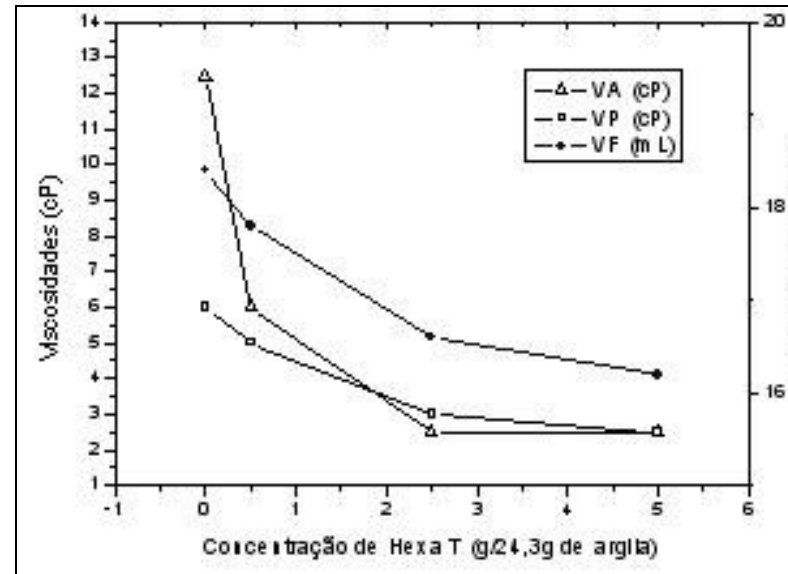

(a)

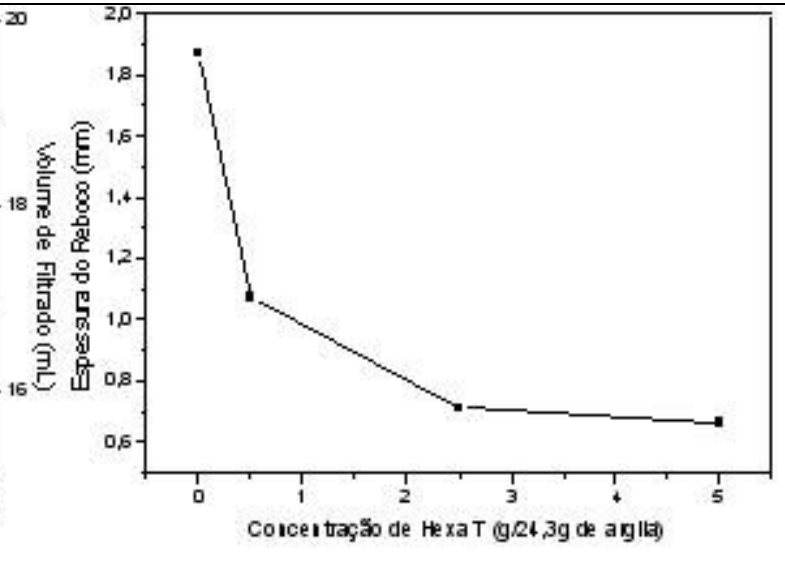

(b)

Figura 9 - Caracterização do Hexa T: (a) Propriedades Reológicas e (b) Espessura do Reboco dos Fluidos Preparados com a Argila Brasgel PA Tratados com o Hexa T.

Figure 9 - Characterization of the Hexa T: (a) Rheological Properties and (b) Filter-cake Thickness of the Fluids Prepared with Brasgel PA Clay and Treated with the Hexa T.

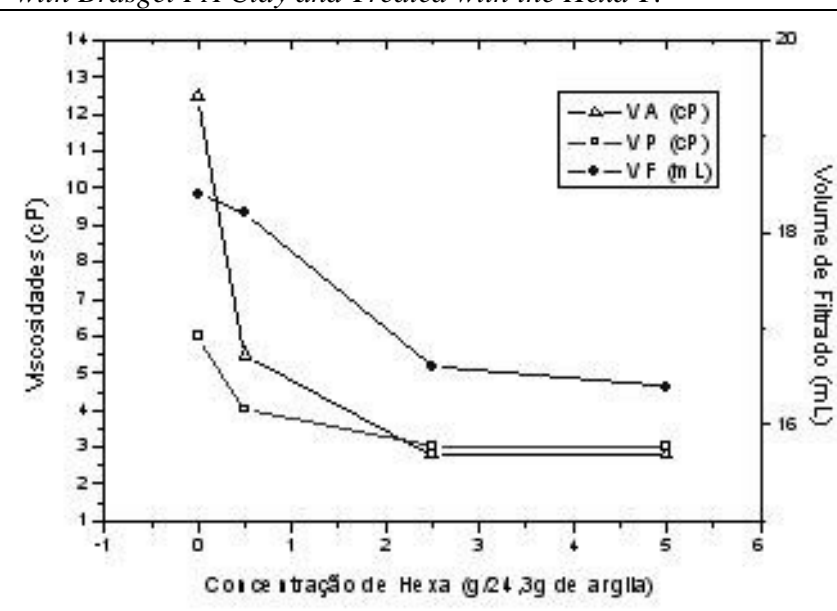

(a)

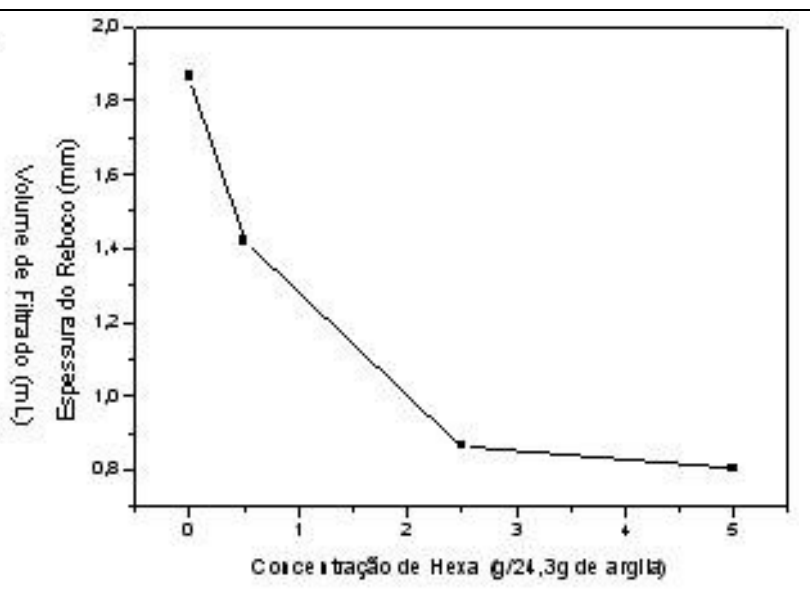

(b)

Figura 10 - Caracterização do Hexa: (a) Propriedades Reológicas e (b) Espessura do Reboco dos Fluidos Preparados com a Argila Brasgel PA Tratados com o Hexa.

Figure 10 - Characterization of the Hexa: (a) Rheological Properties and (b) Filter-cake Thickness of the Fluids Prepared with Brasgel PA Clay and Treated with the Hexa.

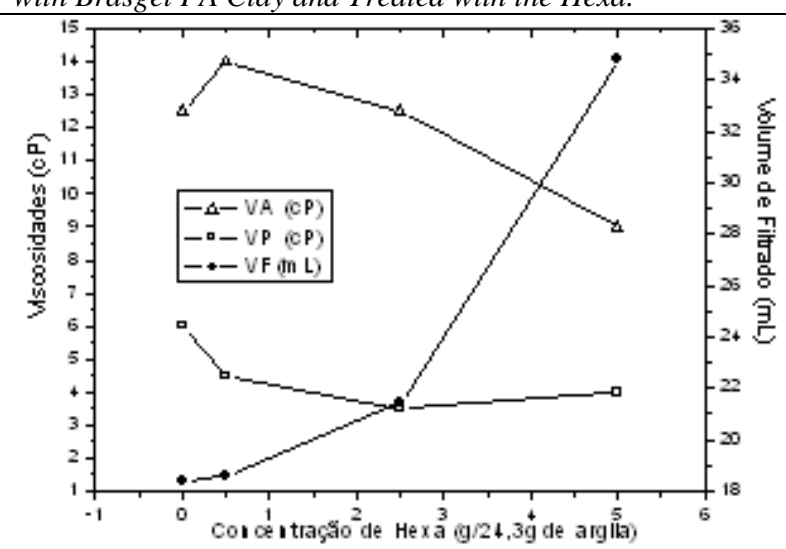

(a)

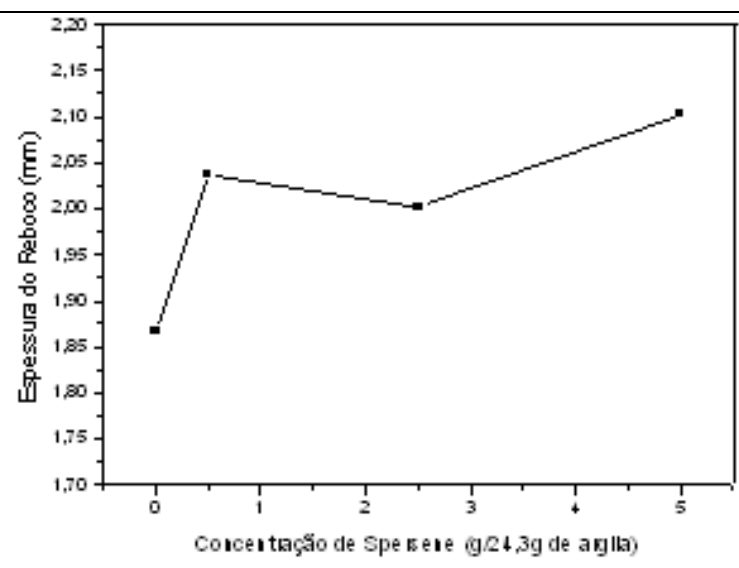

(b)

Figura 11 - Caracterização do Spersene: (a) Propriedades Reológicas e (b) Espessura do Reboco dos Fluidos treparados com a Argila Brasgel PA tratados com o Spersene.

Figure 11 - Characterization of the Spersene: (a) Rheological Properties and (b) Filter-cake Thickness of the Fluids Prepared with Brasgel PA Clay and Treated with the Spersene. 


\section{INFLUENCIA DOS TENSOATIVOS REOLOGIA, NO FILTRADO E REBOCO}

Os resultados obtidos antes e após a incorporação dos aditivos Hexa, Hexa $\mathrm{T}$ e Spersene aos fluidos hidroargilosos estão apresentados nas figuras 12 a 17.

Para os fluidos preparados com a argila Brasgel PA e tratados com o Hexa (Figura 12) observou-se diminuição da VA, variando de $13,6 \mathrm{cP}$ para o fluido preparado sem aditivação, a $8,8 \mathrm{cP}$ para o fluido aditivado com $0,300 \mathrm{~g}$ de Hexa. A VP e o VF praticamente não sofreram alteração e apresentaram, para todos os teores estudados, valores de acordo com as especificações da Petrobras (1998a), mínimo de $4,0 \mathrm{cP}$ para VP e máximo de $18,0 \mathrm{~mL}$ para VF. Apenas a VA não se enquadrou nos limites especificados, que é de no mínimo de 15,0cP. A ER sofreu um aumento de $2,02 \mathrm{~mm}$ para $2,31 \mathrm{~mm}$ com a adição de 0,025 g de Hexa e com o aumento do seu teor, observou-se uma redução, atingindo um valor mínimo de $1,65 \mathrm{~mm}$ para os teores de 0,250 $\mathrm{g}$ e 0,300 $\mathrm{g}$ (do aditivo Hexa).

Para os fluidos preparados com a argila Brasgel PA e tratados com o Hexa T (com tensoativo) (Figura 13) observou-se comportamento semelhante ao apresentado pelos fluidos aditivados com o Hexa (sem tensoativo), ou seja, queda nos valores de VA, pouca variação de VP e redução nos valores de ER com o aumento do teor do aditivo. A VP e o VF apresentaram valores de acordo com as especificações da Petrobras (1998a) para todos os teores de Hexa T.

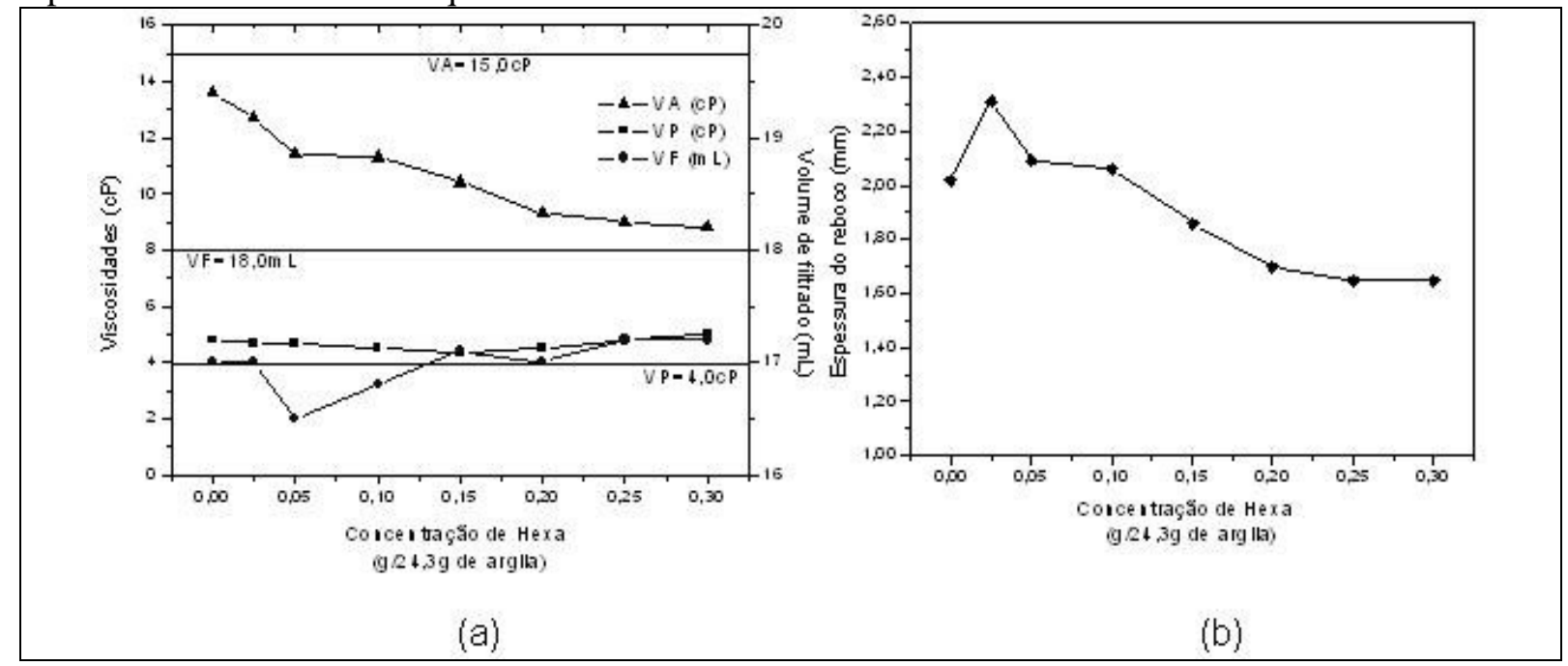

Figura 12 - (a) Propriedades Reológicas e (b) Espessura do Reboco dos Fluidos Preparados com a Argila Brasgel PA tratados com o Hexa.

Figure 12 - (a) Rheological Properties and (b) Filter-cake Thickness of the Fluids Prepared with Brasgel PA Clay and treated with Hexa.

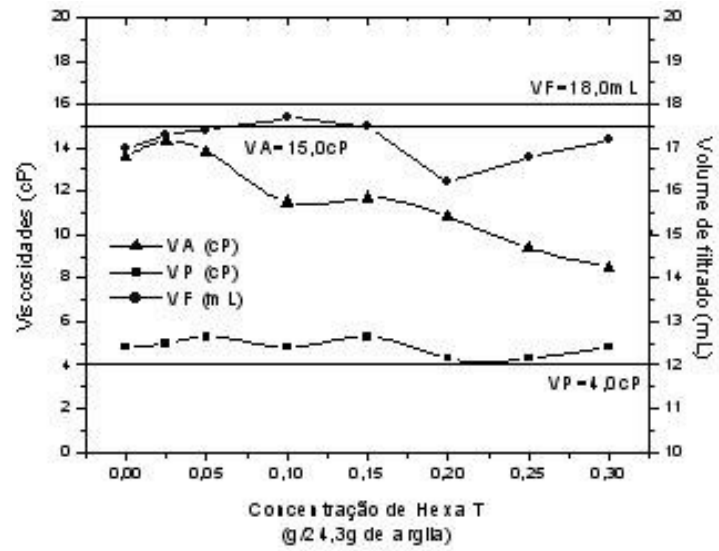

(a)

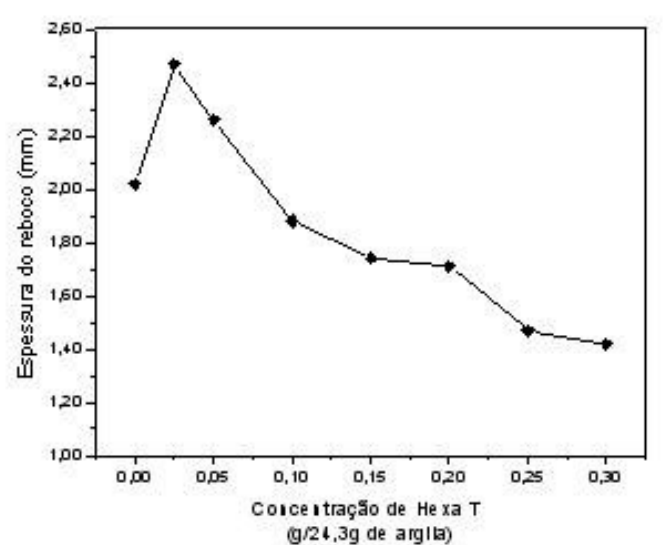

(b)

Figura 13 - (a) Propriedades Reológicas e (b) Espessura do Reboco dos Fluidos Preparados com a Argila Brasgel PA tratados com o Hexa T.

Figure 3 - (a) Rheological Properties and (b) Filter-cake Thickness of the Fluids Prepared with Brasgel PA Clay and treated with Hexa T. 
Para os fluidos preparados com a Brasgel PA e tratados com $0,025 \mathrm{~g}$ de Hexa T, a VA foi de $14,3 \mathrm{cP}$, valor mais próximo ao mínimo especificado $(15,0 \mathrm{cP})$. A ER foi reduzida com o aumento do teor do aditivo, de 2,02 $\mathrm{mm}$ para o fluido sem aditivação a $1,42 \mathrm{~mm}$ para o fluido aditivado com 0,300 g de Hexa $\mathrm{T}$.

A Figura 14 apresenta os resultados obtidos com os fluidos preparados com a argila Brasgel PA aditivados com o Spersene. Observam-se variações poucos significativas nos valores de VA, VP e VF. A ER apresentou comportamento inverso ao dos fluidos tratados com os outros aditivos (Hexa e Hexa T), ou seja, a aditivação ao invés de reduzir a espessura do reboco, conduziu a um acréscimo de 2,02 $\mathrm{mm}$ para o fluido sem aditivação para $2,20 \mathrm{~mm}$ para o fluido aditivado com $0,250 \mathrm{~g}$ de Spersene.

Para os fluidos preparados com a argila Brasgel PA, observou-se que a redução de ER foi mais acentuada para os fluidos tratados com o
Hexa T. Essa redução foi de aproximadamente $30 \%$ (de 2,02 a $1,42 \mathrm{~mm}$ ), enquanto que a aditivação com o Hexa proporcionou uma redução de aproximadamente $18 \%$ (de 2,02 a $1,65 \mathrm{~mm}$ ). Esse comportamento evidenciou a ação do tensoativo na redução da ER; as moléculas do tensoativo envolvem as partículas de argilas, que são dispersas do reboco, reduzindo assim a sua espessura.

Para os fluidos preparados com a argila Verde-lodo tratados com o Hexa (Figura 15) observou-se redução de VA com o aumento do teor do aditivo de $13,1 \mathrm{cP}$ a $8,3 \mathrm{cP}$. A VP sofreu um acréscimo de $2,5 \mathrm{cP}$, atingindo o valor de $4,3 \mathrm{cP}$, o qual está de acordo com o valor especificado pela Petrobras (1998a). O VF sofreu variação pouca significativa. A ER foi reduzida a partir da concentração de $0,100 \mathrm{~g}$ do aditivo, atingindo um mínimo de $1,44 \mathrm{~mm}$ para o fluido aditivado com $0,250 \mathrm{~g}$ de Hexa.

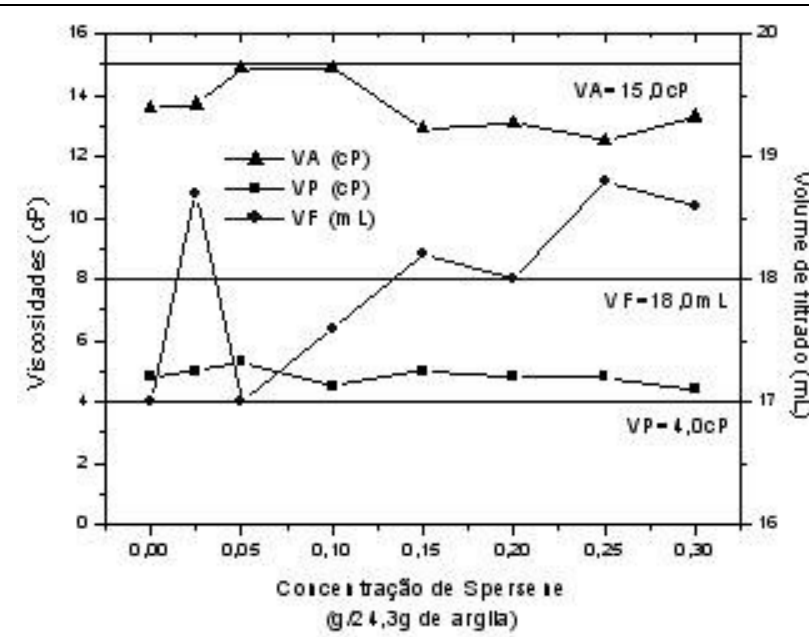

(a)

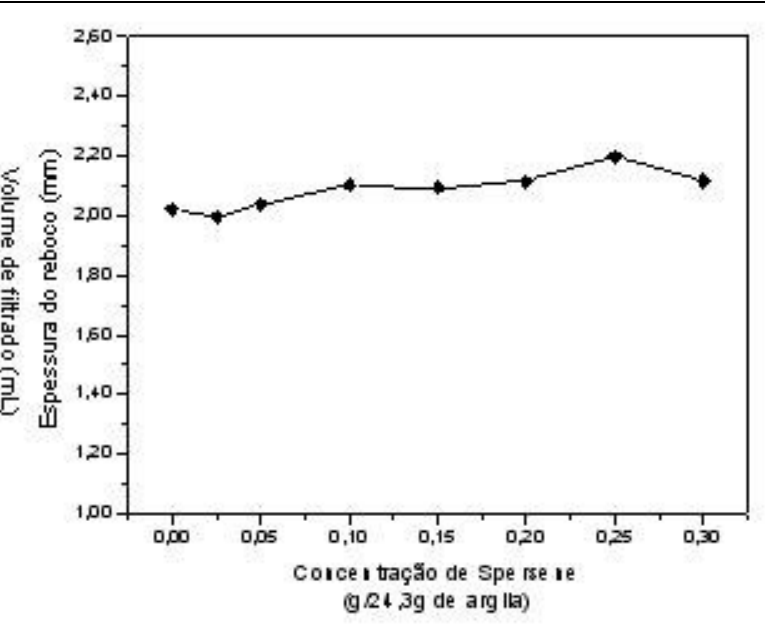

(b)

Figura 14 - (a) Propriedades Reológicas e (b) Espessura do Reboco dos Fluidos Preparados com a Argila Brasgel PA tratados com o Spersene.

Figure 14 - (a) Rheological Properties and (b) Filter-cake Thickness of the Fluids Prepared with Brasgel PA Clay and treated with Spersene.

A figura 16 apresenta os resultados obtidos com os fluidos preparados com a argila Verdelodo tratados com o Hexa $\mathrm{T}$ (com tensoativo). Observou-se comportamento semelhante aos fluidos preparados com a argila Verde-lodo e tratados com o Hexa, ou seja, redução de VA, aumento de VP, atingindo um valor de $4,5 \mathrm{cP}$ (valor de acordo com o especificado pela Petrobras (1998a) para os teores de 0,100g e $0,250 \mathrm{~g}$ de Hexa $\mathrm{T}$ e o VF sofreu poucas variações. A ER foi reduzida com o aumento do teor do aditivo, de $2,40 \mathrm{~mm}$ para o fluido sem aditivação até $1,50 \mathrm{~mm}$ para os fluidos aditivados com os teores de 0,250 g e 0,300 $\mathrm{g}$ do aditivo. 


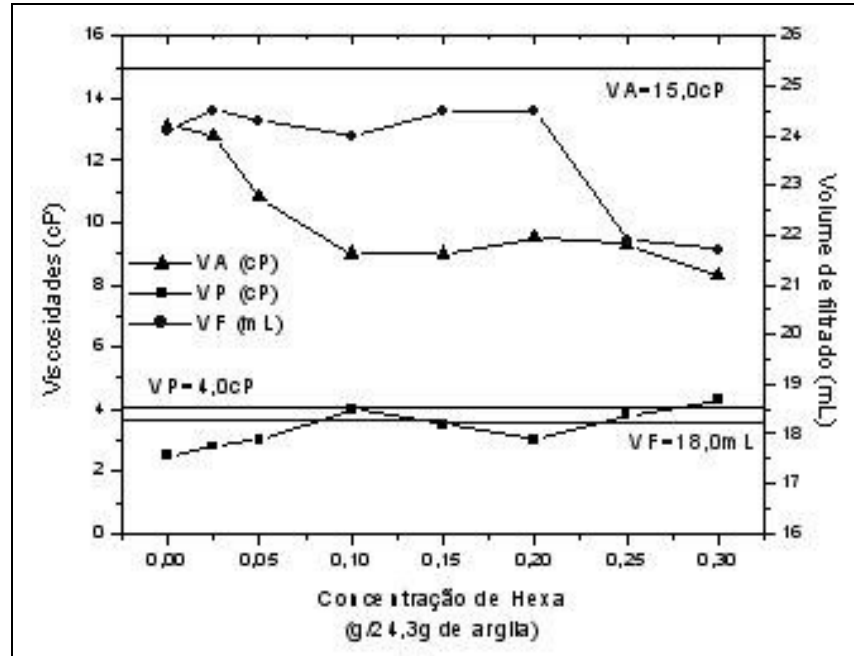

(a)

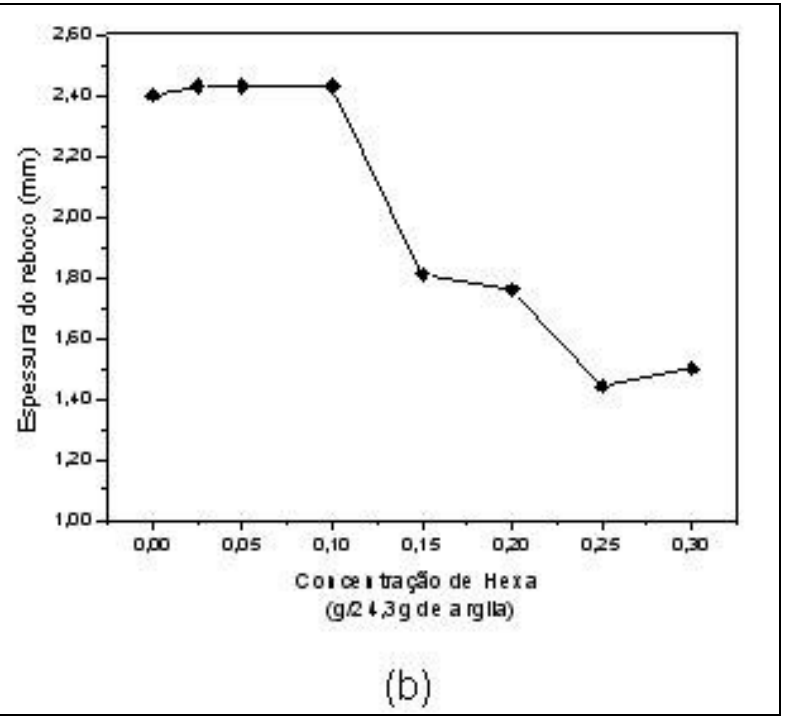

(b)

Figura 15 - (a) Propriedades Reológicas e (b) Espessura do Reboco dos Fluidos Preparados com a Argila Vedelodo tratados com o Hexa.

Figure 15 - (a) Rheological Properties and (b) Filter-cake Thickness of the Fluids Prepared with Verde-lodo Clay and treated with Hexa.

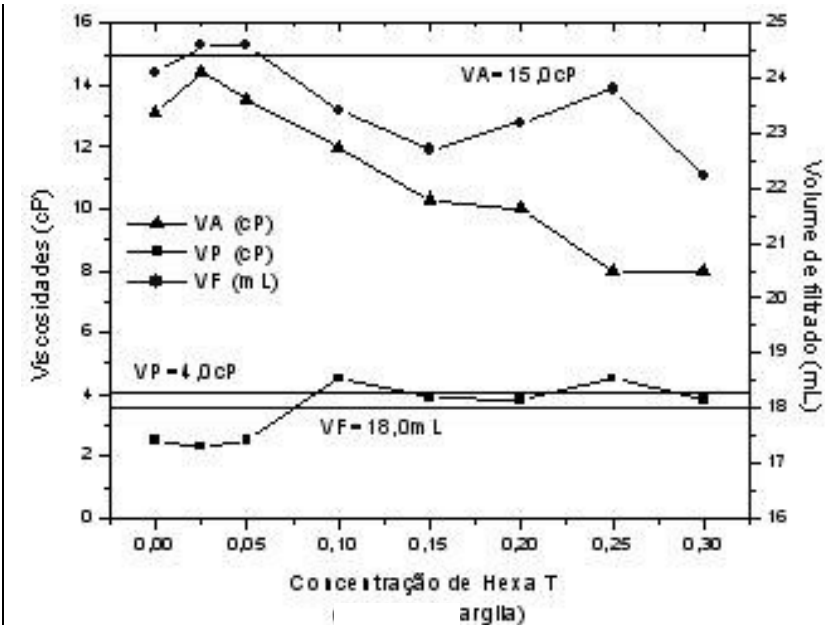

(a)

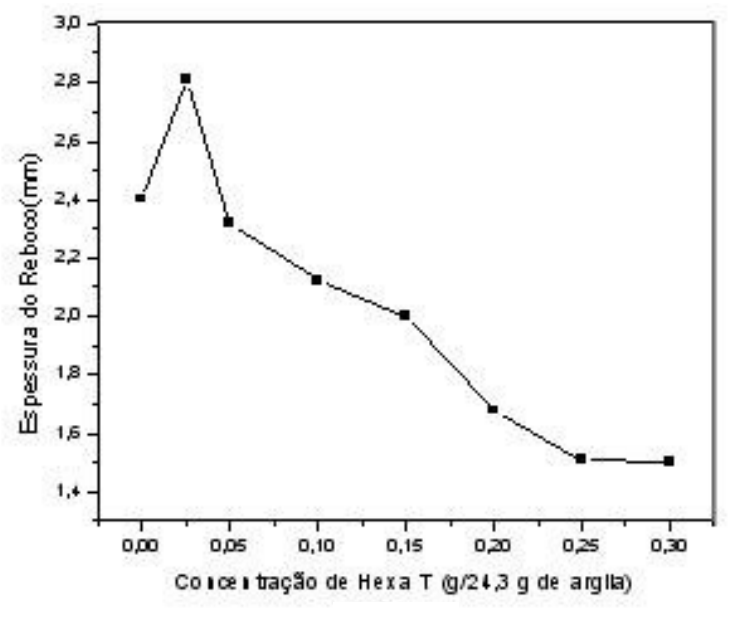

(b)

Figura 16 - (a) Propriedades Reológicas e (b) Espessura do Reboco dos Fluidos Preparados com a Argila Vedelodo tratados com o Hexa $\mathrm{T}$.

Figure 16 - (a) Rheological Properties and (b) Filter-cake Thickness of the Fluids Prepared with Verde-lodo Clay and treated with Hexa T.

A figura 17 apresenta os resultados obtidos com os fluidos preparados com a argila Verdelodo aditivados com o Spersene. Observou-se redução nos valores de VA, acréscimo nos valores de VP e pouca variação nos valores de VF. Ao contrário dos fluidos aditivados com o Hexa e Hexa T, a ER apresentou pouca variação, variando de $2,40 \mathrm{~mm}$ para o fluido sem aditivação a 2,10 $\mathrm{mm}$ para o fluido aditivado com $0,300 \mathrm{~g}$ de Spersene.

Para os aditivos Hexa (sem tensoativo) e Hexa T (com tensoativo), a redução da espessura do reboco para os fluidos preparados com a argila
Verde-lodo foi de 37,5\%, atingindo um valor de $1,50 \mathrm{~mm}$. É importante ressaltar que este valor de ER foi obtido com o aditivo contendo o tensoativo (Hexa T) numa concentração inferior ao obtido com o Hexa, evidenciando novamente a importância do tensoativo na redução da espessura do reboco.

Uma análise conjunta dos resultados mostra que o tratamento dos fluidos preparados com as argilas Brasgel PA e Verde-lodo e tratados com os aditivos dispersantes Hexa e Hexa $T$ proporciona redução na VA e na ER e variações pouco significativas no VF e na VP. 


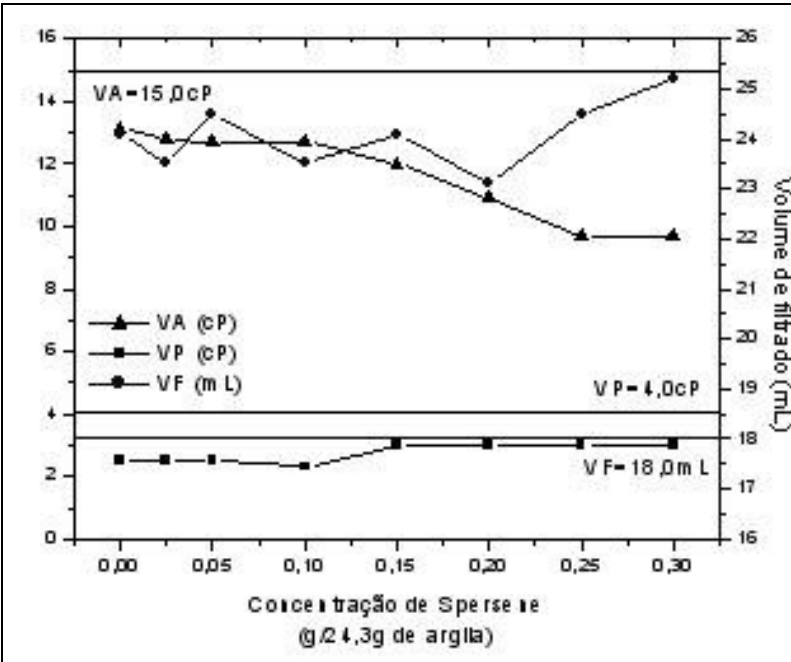

(a)

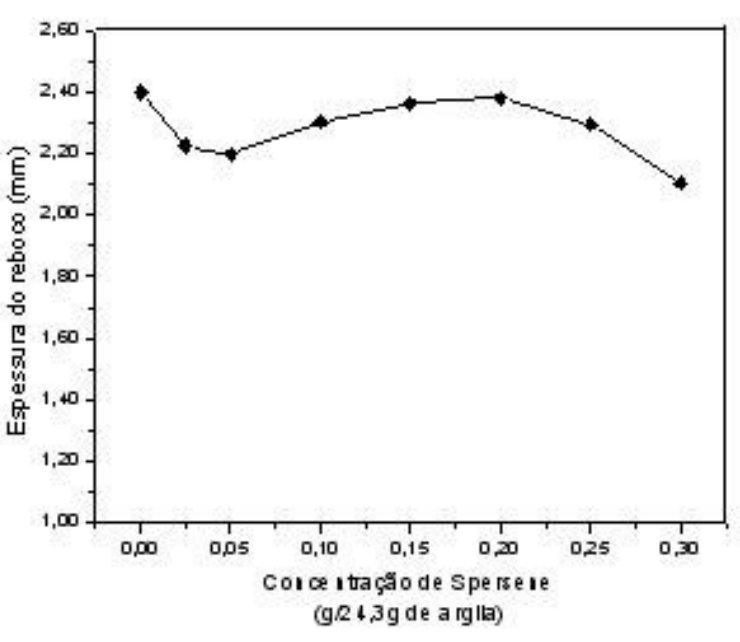

(b)

Figura 17 - (a) Propriedades Reológicas e (b) Espessura do Reboco dos Fluidos Preparados com a Argila Verdelodo tratados com o Spersene.

Figure 17 - (a) Rheological Properties and (b) Filter-cake Thickness of the Fluids Prepared with Verde-lodo Clay and treated with Spersene.

A diminuição de VA deve-se à ação dispersante dos aditivos, que tem como função diminuir a viscosidade do sistema. Embora a aditivação tenha conduzido à diminuição de VA (sistema menos floculado), o VF não apresentou variações significativas, ou seja, a aditivação com o Hexa e Hexa T proporciona também o controle do filtrado. Para os fluidos preparados com as argilas Brasgel PA e Verde-lodo e aditivados com o Spersene, aditivo tradicionalmente utilizado na indústria de petróleo como redutor de viscosidade e controlador de filtrado e reboco, não foram observadas alterações significativas em VA, VP, VF e na ER.

\section{INFLUÊNCIA DOS TENSOATIVOS NO DESENVOLVIMENTO}

O ensaio denominado de "Ensaio do Disco Boiando" objetivou simular o efeito da solução de tratamento ("colchão lavador") sobre o reboco. Os resultados foram bastante satisfatórios evidenciando a redução expressiva na espessura do reboco (Figura 18). Os aspectos e texturas dos rebocos demonstraram total facilidade no descolamento destes do papel de filtro, como apresentado nas figuras 19 a 22 .

Os resultados evidenciaram novamente a maior eficiência na redução da espessura do reboco quando do uso do dispersante Hexa $\mathrm{T}$
(Figura 18 a) em comparação com o Hexa (Figura 18 b). Também a tendência em fazer $o$ reboco descolar do papel e o aspecto de sua textura em estar se desfazendo foram notórios (Figura 19). Os resultados de Spersene demonstraram novamente (item 3.1) a necessidade de dosagens altas para um efeito positivo (Figura $18 \mathrm{c}$ ). Neste caso, o ensaio partiu de um ER inicial mais fino e alcançou ER final também mais fino (Figura 18 c) que os outros, mas a tendência em descolar do papel e o aspecto de textura desmanchando-se não ocorreu (Figura 21).

Foi executada uma segunda etapa de ensaios utilizando-se hipoclorito de sódio, uma vez que é comum aplicá-lo na fase de desenvolvimento dos trabalhos de campo. As dosagens da solução de tratamento foram $3 \%(30 \mathrm{~g} / \mathrm{L})$ de hipoclorito de sódio $10 \%$. A finalidade deste ensaio foi o de verificar se o hipoclorito, usado para degradar polímeros no desenvolvimento de poços construídos com fluidos poliméricos, tem alguma influência na remoção das argilas hidratáveis presentes nos rebocos. Como os rebocos continham somente bentonita tipo Brasgel PA, os resultados não mostraram influência do cloro em afinar reboco (Figura 18 d), somente uma tendência no reboco descolar do papel após $6 \mathrm{~h}$ (Figura 22). 


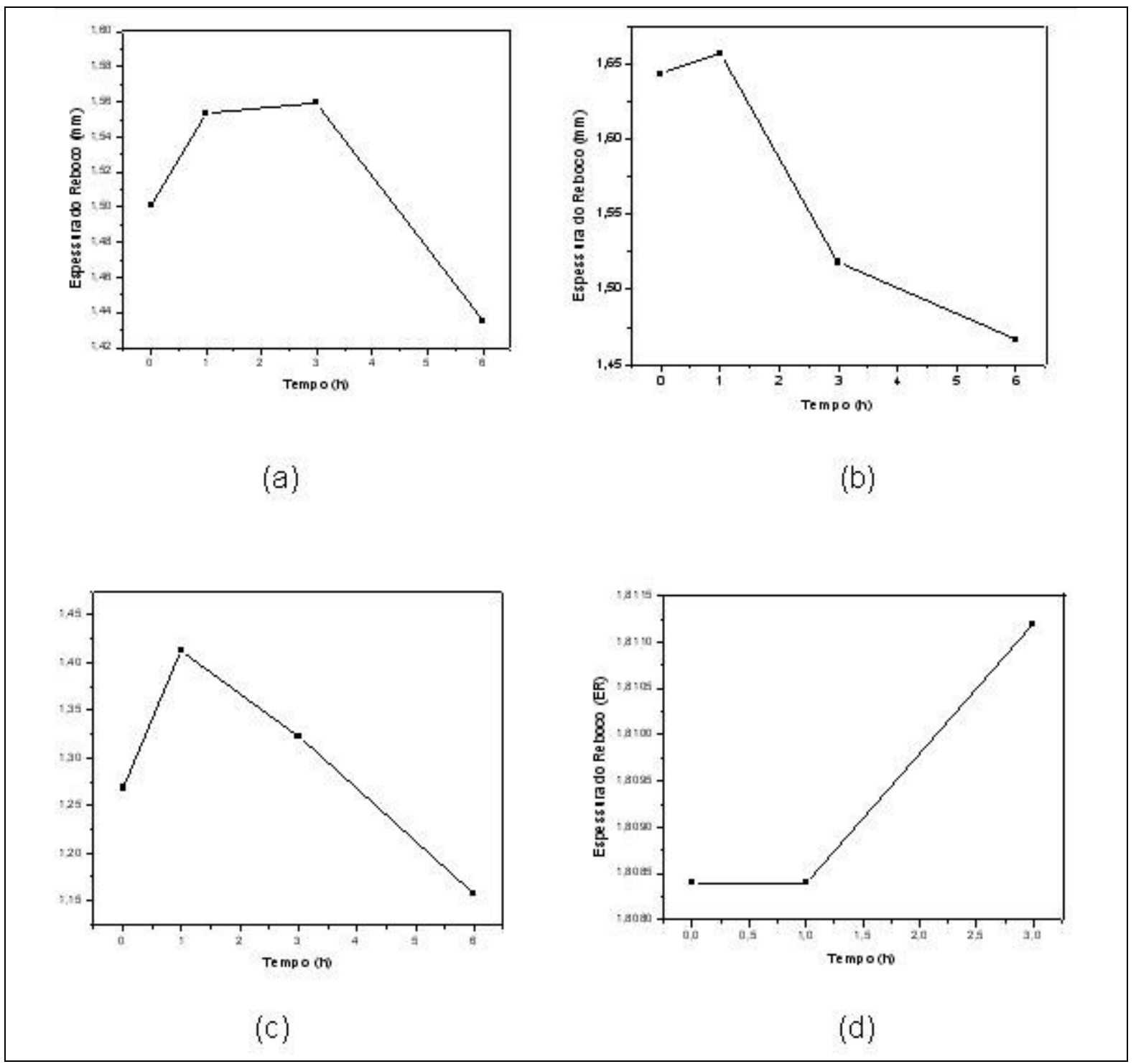

Figura 18 - Espessura do Reboco (a) Reboco imerso na solução de 3,4\% de Hexa, (b) Reboco imerso na solução de 3,4 \% de Hexa T, (c) Reboco imerso na solução de 3,4 \% de Spersene e (d) Reboco imerso na solução de Hipoclorito de Sódio.

Figure 18. Filter-cake Thickness (a) Filter-cake immersed on the 3.4\% Hexa solution, (b) Filter-cake immersed in the $3.4 \%$ Hexa T solution, (c) Filter-cake immersed in the 3.4\% Spersene solution and (d) Filter-cake immersed in Hypochlorite of Sodium solution

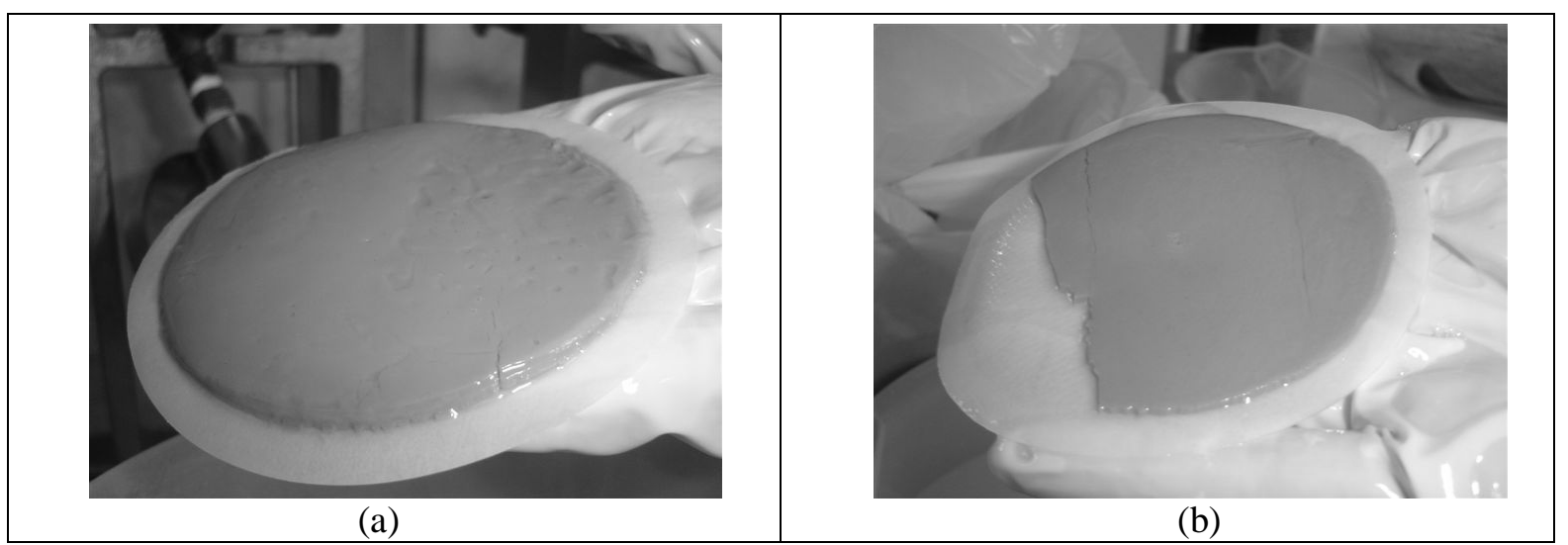

Figura 19 - (a) Reboco Inicial e (b) Reboco Após 6 h na Solução de 3,4\% de Hexa T. Figure 19 - (a) Initial Filter-cake and (b) Filter-cake After $6 \mathrm{~h}$ on the 3.4\% Hexa T Solution. 


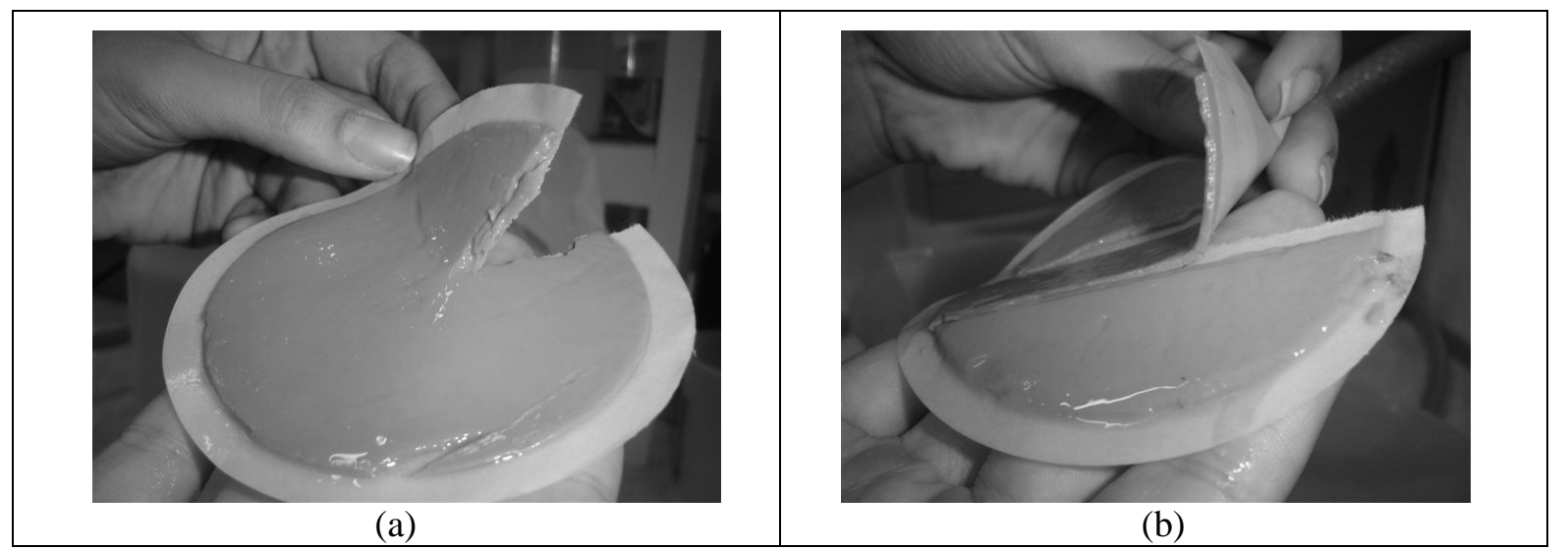

Figura 20 - (a) Reboco Inicial e (b) Reboco após 6 h na solução de 3,4\% de Hexa.

Figure 20 - (a) Initial Filter-cake and (b) Filter-cake after 6 h on the 3.4\% Hexa solution.

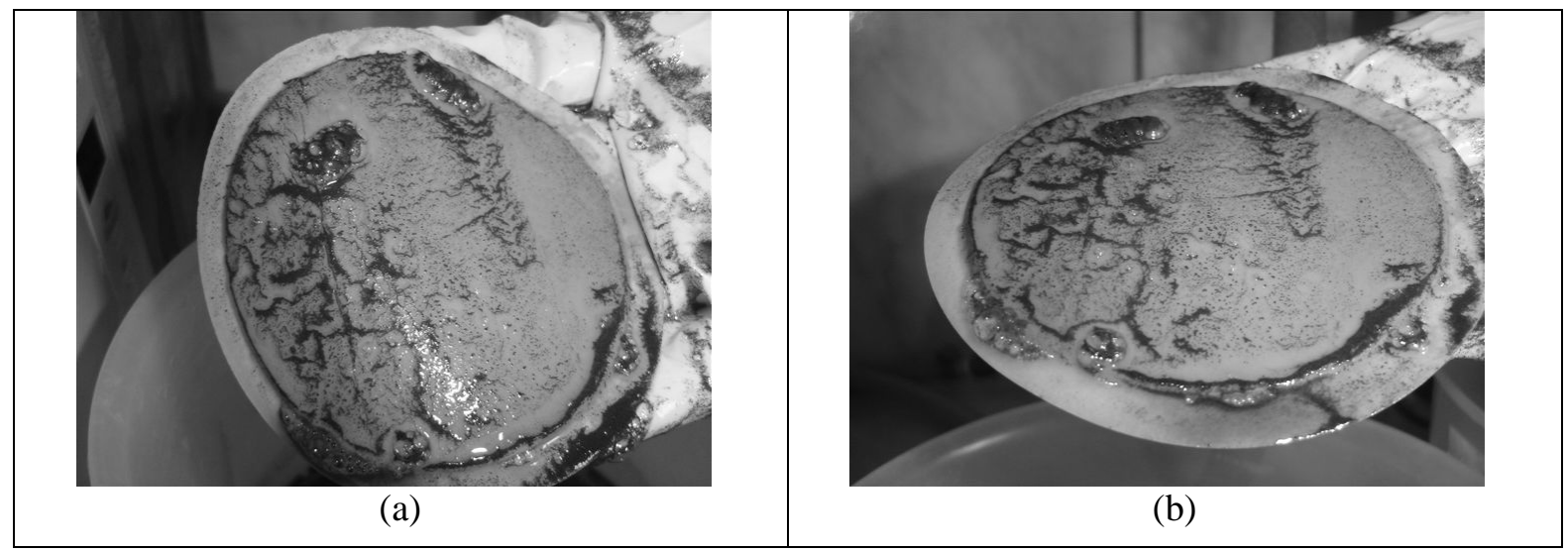

Figura 21 - (a) Reboco após 3 h e (b) Reboco após 6 h na solução 3,4\% de Spersene.

Figure 21 - (a) Filter-cake after $3 h$ and (b) Filter-cake after $6 h$ on the 3,4\% Spersene solution.

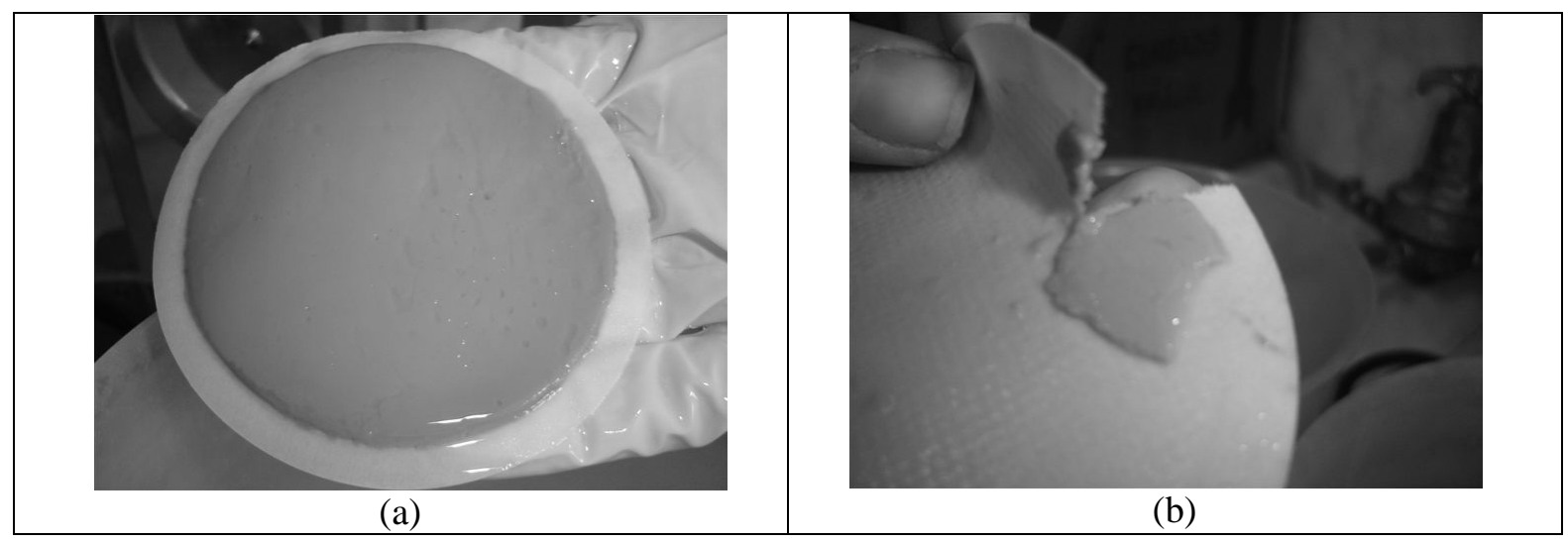

Figura 22 - (a) Reboco após 1 h e (b) Reboco após 6h na solução de Hipoclorito de Sódio.

Figure 22 - (a) Filter-cake after $1 \mathrm{~h}$ and (b) Filter-cake after $6 \mathrm{~h}$ on the Hypochlorite of Sodium solution.

\section{CONCLUSÕES}

Com o objetivo de avaliar a aplicação de dispersantes com e sem tensoativos no controle do reboco, do filtrado e da reologia de fluidos hidroargilosos, bem como na etapa de desenvolvimento de poços tubulares, conclui-se que:

- a aditivação com o Hexa T (com tensoativo) e com o Hexa (sem tensoativo) reduziu a VA dos fluidos preparados com as argilas Brasgel PA e Verde-lodo, sem alterar a VP e o VF;
- para os fluidos preparados com a argila Brasgel PA, a aditivação com o Hexa reduziu ER em aproximadamente $18 \%$, enquanto que na aditivação com o Hexa $\mathrm{T}$ esta redução foi de aproximadamente $30 \%$;

- a redução da espessura do reboco para os fluidos preparados com a argila Verde-lodo foi de $37,5 \%$ para os dois aditivos estudados. Sendo que este valor foi obtido numa concentração inferior para os fluidos aditivados com o Hexa T e

- para os fluidos preparados com as argilas Brasgel PA e Verde-lodo tratados com o 
Spersene, não foram observadas variações significativas na VA, VP e VF. Embora o Spersene seja o aditivo mais tradicionalmente utilizado, ele não apresenta ação efetiva na redução da espessura do reboco nas concentrações utilizadas. Os Ensaios de Caracterização (item 3.1) e o Ensaio do Disco Boiando (item 3.3; Figuras 18 (c) e 21) indicaram uma tendência de maior eficiência para dosagens acima de $3 \mathrm{~g}$ que necessita ser melhor estudada.

- o Ensaio do Disco Boiando demonstrou que a utilização de dispersantes em soluções para desenvolvimento de poços, principalmente durante a descida do pré-filtro ("colchão lavador"), pode ser benéfica para a necessária remoção do reboco no processo de limpeza do poço. $\mathrm{O}$ aditivo Hexa $\mathrm{T}$, pelo que se observou fisicamente e pelos resultados de ER, também se apresentou mais eficiente que os demais. O Spersene demonstrou-se como opção em dosagens acima de 3\%. O hipoclorito de sódio não reduziu a espessura do reboco, nem alterou significativamente a sua textura. Sua aplicação merece estudos mais aprofundados, pois é difícil transpor para as paredes do poço a tendência demonstrada em soltar o reboco do papel de filtro (Figura 22 (b)).

Em resumo, a ação reativa do tensoativo presente no Hexa $T$ foi evidenciada por meio da redução significativa do ER e controle de VF dos fluidos estudados, bem como que aditivos à base de polifosfatos são mais eficientes como dispersantes e redutores da espessura do reboco. Esta constatação mostra ainda a importância da utilização conjunta de agentes dispersantes e tensoativos na formulação de aditivos a serem empregados em fluidos hidroargilosos na prevenção ou solução de problemas causados pela presença de rebocos muito espessos e também como um auxiliar importante nos processos de desenvolvimento. 


\section{REFERÊNCIAS}

API, Norma API Recommended Practice 13B-1, novembro, 2003.

BENNA, M., KBIR- ARIGUIB, N., CLINARD, C., BERGAYA, F. Static Filtration of Sodium Bentonite Clay Suspensions. Effect of Clay Content. Applied Clay Science v. 19, p.103-120, 2001.

FERRAZ, A.I. Manual de engenharia dos fluidos de perfuração, Divisão Magcobar Grupo Oilfield Products Dresser Industries, 1977.

GUNGOR, N.; ALEMDAR, A.; ATICI, O, Ece, I.O. The Effect of Surfactant on the Flow and Potencial of Bentonite Suspensions. Materials Letters v. 51, p. 250-254, 2001.

LUMMUS, J.L; AZAR, J.J. Drilling fluids optimization A practical field approach, PennWell Publishing Company, Tulsa, Oklahoma, 1986.

PEREIRA, E., Uso de Inibidores de Argilas como Solução de Problemas em Sondagem, Disponível em <www.systemmud.com.br>. Acesso em: 18 de junho de 2003.
PETROBRAS. Ensaio de Viscosificante para Fluido de Perfuração Base de Água na exploração e Produção de Petróleo, Método, N-2605, 1998.

PETROBRAS. Viscosificantes para Fluido de Perfuração Base de Água na Exploração e Produção de Petróleo, Especificação, N-2604, 1998a. PIRES, A.R.P., Síntese e Propriedades de Soluções de Tensoativos Catiônicos Derivados de (3Dimetilaminipropil) amidas de Ácidos Carboxílicos, Tese (Doutorado em Engenharia Química). Universidade de São Paulo - USP; 2002.

\section{AGRADECIMENTOS}

Os autores agradecem ao Geól. Marcelo Roselli pelas sugestões ao tema do trabalho, à Agência Nacional do Petróleo - ANP, a FINEP, ao CTBRASIL e ao $\mathrm{CNPq} / \mathrm{CTPETRO}$ pelo apoio financeiro; à Empresa System Mud Indústria e Comércio Ltda. pelo fornecimento dos aditivos; ao CNPq pela concessão da bolsa DCR, processo $\mathrm{N}^{\circ}$ 309873/2003-7 e ao LABDES pelo o uso de suas instalações e apoio à pesquisa. 